\title{
Effect of interleukin 2 on killer cell inhibitory receptors in patients with rheumatoid arthritis
}

\author{
T Kogure, A Niizawa, L X Hai, H Fujinaga, Y Shimada, H Ochiai, K Terasawa
}

\begin{abstract}
Objective-The genes for killer cell inhibitory receptors (KIRs) have been cloned and their functions and responses to other molecules, including cytokines, have been partially clarified. However, the expression of KIRs has not been analysed in patients with autoimmune diseases, such as rheumatoid arthritis (RA), who are highly susceptible to microbial infection. Therefore, KIR expression on lymphocytes in patients with RA, and the regulation of KIR expression by interleukin 2 (IL2) in RA was investigated. Methods-CD158a/b expression on peripheral blood mononuclear cells (PBMC) obtained from 25 patients with RA and 14 healthy subjects was analysed by flow cytometry. Additionally, PBMC from the two groups of subjects were cultured in RPMI 1640 medium with or without IL2 for 48 hours, and then their CD158a/b expression was analysed.

Results-The rate of CD158a expression on the CD8+ cells was lower in patients with RA than in healthy subjects, though there was no significant difference in the CD158a/b expression on the CD16+ cells between the two groups. The upregulation of CD16+CD158a/b+ cells in response to IL2 was significantly reduced in patients with RA compared with healthy subjects. Conclusion-The reduced induction of KIR expression in response to IL2 may provide insight into the reason for the high susceptibility of patients with RA to microbial infection.

(Ann Rheum Dis 2001;60:166-169)
\end{abstract}

In 1995 the molecular cloning of novel natural killer (NK) receptors was reported, ${ }^{1-3}$ and it was subsequently shown that the receptors transmit negative signals. ${ }^{45}$ These receptors are now called killer cell inhibitory receptors (KIRs). It is widely accepted that the expression of KIRs plays a part in the cytotoxic function of NK cells. Analysis of KIR expression has contributed to determining the mechanism of NK cytotoxicity.

Several monoclonal antibodies to KIRs have been established. Antibody EB6 (antiCD158a) reacts with KIR2DL1 and
KIR2DS1, and GL183 (anti-CD158b) reacts with KIR2DL2, KIR2DL3, and KIR2DS2. ${ }^{6}$ KIR2DL1, 2, and 3 each contain an immunoreceptor tyrosine based inhibition motif. KIR2DL1 recognises HLA-Cw4, 5, 6, and KIR2DL2, 3 recognise HLA-Cw1, 3, 7, 8. ${ }^{6} 7$ Using these monoclonal antibodies, we have recently shown that the expression of both CD158a and CD158b on lymphocytes is upregulated by interleukin 2 (IL2) but not by interferon $\gamma$ or IL4, though IL2 enhances the cytotoxicity of NK cells. ${ }^{8}$ It is considered that the upregulation of KIRs by IL2 results in enhanced ability to sort target cells, such as viral infected cells from uninfected cells, according to major histocompatibility complex (MHC) class I expression.

NK cytotoxicity decreases in patients with some autoimmune diseases, such as systemic lupus erythematosus, Crohn's disease, and rheumatoid arthritis (RA). ${ }^{9-11}$ It is known that patients with these diseases have increased susceptibility to microbial infection. For RA, a clinicopathological study of 81 patients at necropsy found that the cause of death was related to infection in $23.5 \%$ of cases. ${ }^{12}$ Patients with RA have increased susceptibility to $\mathrm{Myco}$ bacterium tuberculosis (TB) owing to treatment with corticosteroids or immunosuppressant drugs $^{13}$ and the defective immune status of patients with RA. ${ }^{14}$ In humans, CD $4+\mathrm{T}$ cells are thought to have a major role in antimycobacterial immunity. ${ }^{15}$ Additionally, several lineages of lymphocytes, such as CD8+ T cells or NK cells, may play a crucial part in the protection against TB infection through cytotoxic responses. ${ }^{16}{ }^{17}$ Thus it is important from a clinical viewpoint to investigate the immune response of $\mathrm{NK}$ cells obtained from the patients who are highly susceptible to microbes such as TB. However, as KIR expression on NK cells has not been analysed in patients with

Table 1 Percentage of killer cell inhibitory receptor expressing cells in the peripheral blood mononuclear cells of patients with rheumatoid arthritis and healthy controls. Results are shown as means (SD)

\begin{tabular}{lll}
\hline Cell population (\%) & $\begin{array}{l}\text { Healthy controls } \\
(n=14)\end{array}$ & $\begin{array}{l}\text { Patients with } R A \\
(n=25)\end{array}$ \\
\hline CD16 CD158a & $1.68(1.43)$ & $1.13(1.22)$ \\
CD16 CD158b & $5.52(4.58)$ & $6.61(3.76)$ \\
CD8 CD158a & $1.03(0.58)$ & $0.61(0.48)^{\star}$ \\
CD8 CD158b & $2.51(1.66)$ & $2.40(1.47)$
\end{tabular}

${ }^{\star} \mathrm{p}<0.05$ in Mann-Whitney's U test.
Accepted for publication 15 May 2000 
RA we analysed this and the regulation of KIR expression by IL2 in patients with RA compared with healthy subjects.
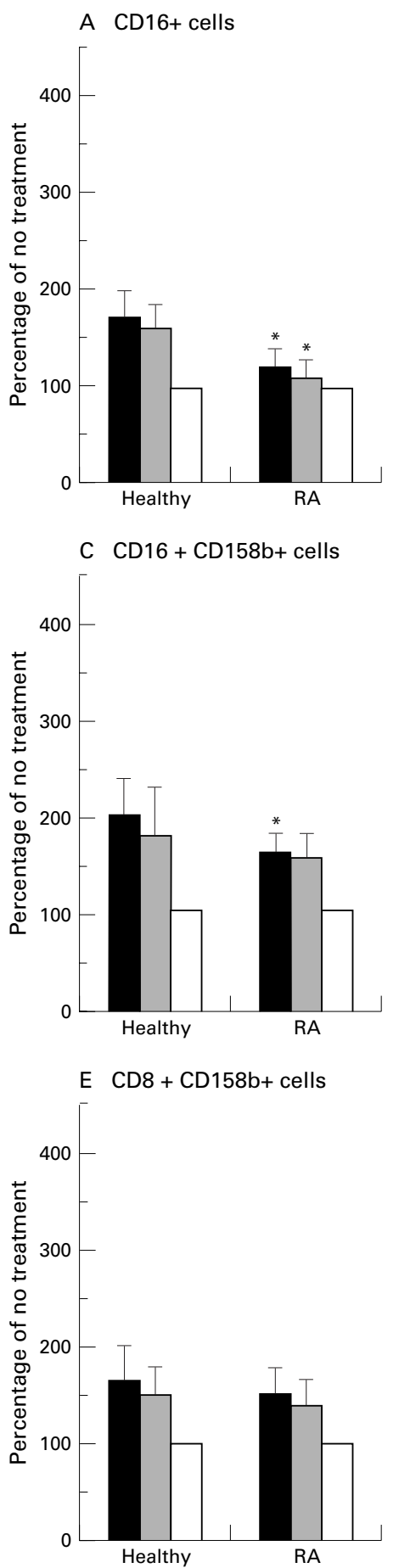

Figure 1 Regulation of CD158a and CD158b expression by interleukin 2 (IL2) in healthy subjects and patients with rheumatoid arthritis $(R A) .{ }^{\star} p<0.05$ versus healthy subjects in each cell population. (A) Although the population of CD16+ cells was significantly increased by treatment with IL2 (versus no treatment in each group), the increase of CD16+ cells was significantly less in $R A$ than in healthy controls. (B) The increase of $C D 16+C D 158 a+$ cells was significantly less in $R A$ than in healthy controls by treatment with IL2 at 50 and $200 \mathrm{U} / \mathrm{ml}$. (C) The increase of CD16+CD158b+ cells was significantly less in RA than in healthy controls for treatment with IL2 at 200 U/ml but not $50 \mathrm{U} / \mathrm{ml}$. (D) The increase of $C D 8+C D 158 a+$ cells was significantly less in $R A$ than in healthy controls for treatment with IL2 at both 50 and $200 \mathrm{U} / \mathrm{ml}$. (E) The increase of $C D 8+C D 158 b+$ cells was lower in patients with $R A$ than in healthy subjects, though the difference was not significant.

\section{Methods}

HEALTHY SUBJECTS AND PATIENTS

Twenty five patients (19 female, six male) with flares of RA as defined by the revised criteria of the American College of Rheumatology ${ }^{18}$ were included in this study. The characteristics of these patients, given as means (SD), were as follows: age 56.3 (11.4) years (range 23-72), disease duration 8.1 (6.2) years (range 2-24), erythrocyte sedimentation rate $78(41) \mathrm{mm} / 1 \mathrm{st}$ h (range 36-113), $\mathrm{CH}_{50}$ (serum complement titre/50\% haemolytic unit of complement) 36.9 (7.0) $\mathrm{U} / \mathrm{ml}$ (range 26-52), anatomical stage ${ }^{19}$ 2.3 (1.3), and functional class ${ }^{19} 2.1$ (0.9). All were receiving non-steroidal anti-inflammatory drugs. Two were also taking bucillamine, three gold sodium thiomalate, and four prednisolone (2.5-7.5 mg/day). None was receiving methotrexate. Peripheral blood from 14 healthy, age matched volunteers (53.3 (14.8) years) was used.

\section{REAGENTS}

Fluorescein isothiocyanate (FITC) conjugated antihuman CD8, FITC-antihuman CD16, phycoerythrin (PE) conjugated antihuman CD158a (EB6), and PE conjugated antihuman CD158b (GL183) were purchased from Immunotech, Marseille, France. Recombinant human IL2 was obtained from Pharmabiotechnology, Hanover, Germany.

\section{CELLS}

Peripheral blood mononuclear cells obtained from 14 healthy subjects and 25 patients with RA were separated from heparinised blood by Lymphoprep (Nyegaard, Oslo, Norway) gradient centrifugation. ${ }^{20}$ They were incubated in a culture dish in a humidified 5\% $\mathrm{CO}_{2} / 95 \%$ air atmosphere at $37^{\circ} \mathrm{C}$ for 60 minutes. After the incubation, non-adherent cells were collected and washed twice in phosphate buffered saline (PBS).

\section{CELL CULTURE}

One million cells were cultured in RPMI 1640 medium supplemented with $10 \%$ fetal calf serum (Biological Industries, Israel) in tissue culture dishes (Becton Dickinson, Franklin, NJ). The cell cultures were incubated in medium only, or medium with IL2 at 50 or 200 $\mathrm{U} / \mathrm{ml}$, in a humidified $5 \% \mathrm{CO}_{2} / 95 \%$ air atmosphere at $37^{\circ} \mathrm{C}$ for 48 hours. After each incubation, cells were collected and their surface antigens analysed by flow cytometry (Epics XL, Beckman Coulter, France). Each experiment was carried out in duplicate.

\section{CELL PHENOTYPE}

Surface phenotyping was carried out by a two colour immunofluorescence staining technique, with isotype-specific mouse antihuman antibody conjugated with either FITC or PE. ${ }^{21}$ Each sample of stained cells was suspended in $0.5 \mathrm{ml} \mathrm{PBS}$ and analysed by flow cytometry. Lymphocyte subsets were identified by gating analysis, and fluorescence profiles were obtained for 10000 cells of each sample. 
Negative controls for each experiment were performed with FITC- and PE-labelled mouse IgG.

STATISTICAL ANALYSIS

Data are expressed as mean (SD) values. All data were collected in a computer database and analysed with the StatView-J 4.02 program (Abacus Concept, Berkeley, CA, USA). The Mann-Whitney U test was performed for each set of surface antigens. For all statistical tests $\mathrm{p}<0.05$ was regarded as significant.

\section{Results}

CD158A AND CD158B EXPRESSION IN THE PATIENTS WITH RA

Table 1 summarises the degree of CD $158 \mathrm{a} / \mathrm{b}$ expression. The percentage of the number of cells expressing CD158a/b and CD8 or CD16 is shown. There was no significant difference of CD158a or CD158b expression on the CD16+ cells between the patients with RA and healthy subjects. In contrast, the percentage of CD158a expression on the CD8+ cells was lower in the patients with RA than in healthy subjects, though there was no significant difference in CD158b expression.

REGULATION OF CD158A AND CD158B EXPRESSION BY IL2 IN HEALTHY SUBJECTS AND THE PATIENTS WITH RA

The population of CD16+ (an activatory receptor for $\mathrm{NK}$ cells ${ }^{22}{ }^{23}$ ) cells was significantly increased in the patients with RA by treatment with IL2, as shown in a previous study ${ }^{24}$ (fig 1A). At the same time, the percentage of CD16+CD158a/b+ cells was increased in healthy controls (figs $1 \mathrm{~B}$ and $\mathrm{C}$ ), as shown in a recent report. ${ }^{8}$

In this study we assessed the difference of the response of KIR expression (CD158a/b) to IL2 between healthy controls and patients with RA. Figures $1 \mathrm{~B}$ and $\mathrm{C}$ show that the response to IL2 was significantly reduced in patients with RA compared with that in healthy controls. There was a significant difference in CD16+CD158a+ cells when IL2 was used at 50 and $200 \mathrm{U} / \mathrm{ml}$, but a significant difference in CD16+CD158b+ cells only for IL2 at 200 $\mathrm{U} / \mathrm{ml}$. The KIRs were expressed on T cells, so we further analysed the response of KIRs on CD8+ cells (figs $1 \mathrm{D}$ and $\mathrm{E})$. The percentage of CD8+CD158a+ cells that increased in response to IL2 was significantly less in patients with RA than in healthy controls (fig 1D). The increase of CD8+CD158b+ cells was lower in patients with RA than in healthy subjects, though the difference was not significant (fig 1E).

\section{Discussion}

The identification of KIRs raises several interesting questions. How is the expression of KIRs affected by cytokines such as IL2, which activates cytotoxicity, and IL4, which inhibits IL2 induced cytotoxicity? Recently, we showed that IL2, but not interferon $\gamma$ or IL4, upregulates the expression of CD158a/b molecules on lymphocytes. ${ }^{8}$ Because IL2 enhances NK cytotoxicity, ${ }^{25}$ we now consider that IL2 may enhance the ability of NK cells to sort the target cells according to MHC class I expression by the upregulation of KIR expression. It is important from a clinical viewpoint that KIRs are upregulated in response to microbial infections. However, KIR expression has not been analysed in patients with RA, though they are known to have low NK activity ${ }^{11}{ }^{26}$ and high susceptibility to microbes. ${ }^{13} 14$

As far as we know, this is the first investigation to measure the expression of KIRs (CD158a/b) in patients with RA, and to show that the population of CD8+CD158a+ cells is lower in patients with RA than in healthy subjects, and that the upregulation of $\mathrm{CD} 158 \mathrm{a} / \mathrm{b}$ by treatment with IL2 is weaker in patients with RA than in healthy subjects.

The role of NK cells in the propagation of rheumatoid inflammation remains unclear. NK cell function in peripheral blood of patients with RA may be normal ${ }^{27} 28$ or depressed. ${ }^{1125}$ Disease modifying drugs, especially gold treatment, resulted in enhanced circulating NK cell activity as well as a decrease in RA disease activity. ${ }^{29}$ Thus it is important to analyse the functional disorders of NK cells in RA. In this study a less upregulated rate of KIRs by IL2 was found in the patients with RA. It has been shown that IL2 treatment did not restore the NK activity of peripheral blood of patients with RA to normal levels, though the NK activity was enhanced by IL2 treatment in vitro. ${ }^{11}$ Possibly, this is one of the factors that induce the disorder of NK cytotoxicity in RA. However, the association between less upregulation of KIRs and the pathogenesis of RA is still obscure.

A series of immune dysfunctions plays a part not only in the development of inflammatory joints but also in the high susceptibility to microbes in RA. The low response of KIRs to IL2 may be related to a TB infection. T cell mediated, acquired immune response to TB is a complex response believed to involve a variety of cell subsets. In patients with TB, IL2 administration induced the augmentation of NK cell cytotoxity as well as the potentiation of the antimicrobial cellular immune response to TB. ${ }^{17}$ Our finding of a low response of KIRs to IL2 suggests that patients with RA may be highly susceptible to TB. This has certainly been shown, even when the patients with RA are not treated with immunosuppressive drugs. $^{14}$

The significant role of KIR expression on $\mathrm{T}$ cells rather than NK cells is still unclear; however, it is speculated that it may be related to the ability to escape the attack by cytotoxic $\mathrm{T}$ cells which react with autoantigens. There was no significant difference in the CD158a or CD158b expression on CD16+ cells between patients with RA and healthy subjects. In contrast, the rate of CD158a expression on the CD8+ cells was lower in the patients with RA than in healthy subjects. The consequences of the low CD158a expression on CD8+ T cells in RA are still not known; however, this phenomenon may be associated with the self attacking mechanism in autoimmune diseases. 
Further studies will be required to examine this possibility.

Finally, we showed the expression of KIRs (CD158a/b) in patients with RA, and demonstrated that the population of CD8+CD158a+ cells was reduced in patients with RA compared with healthy subjects, and that the upregulation of CD $158 \mathrm{a} / \mathrm{b}$ by the treatment with IL2 was weaker in patients with RA than in healthy subjects.

We thank TS Oda and N Kuribayashi for excellent assistance.

1 Wagtmann N, Biassoni R, Cantoni C, Verdiani S, Malnati MS, Vitale M, et al. Molecular clones of the p58 NK cell receptor reveal immunoglobulin-related molecules with
diversity in both the extra- and intracellular domains. Immunity 1995;2:439-49.

2 Colonna M, Samaridis J. Cloning of immunoglobulinsuperfamily members associated with HLA-C and HLA-B recognition by human natural killer cells. Science 1995; 268:405-8

3 D'Andrea A, Chang C, Franz-Bacon K, McClanahan T, Phillips JH, Lanier LL. Molecular cloning of NKB1 a natural killer cell receptor for HLA-B allotypes. J Immunol 1995; 155:2306-10.

4 Binstadt BA, Brumbaugh KM, Dick CJ, Scharenberg AM, Williams BL, Colonna $M$, et al. Sequential involvement of Lck and SHP-1 with MHC-recognizing receptors on NK cells inhibits FcR-initiated tyrosine kinase activation. Immunity 1996;5:629-38.

5 Vivier E, Daeron M. Immunoreceptor tyrosine-based inhibition motifs. Immunol Today 1997;18:286-91.

6 Colonna M. Specificity and function of immunoglobulin superfamily NK cell inhibitory and stimulatory receptors. Immunol Rev 1997;155:127-33.

7 Morreta A, Biassoni R, Bottino C, Pende D, Vitale M, Poggi A, et al. Major histcompatibility complex class I-specific receptors on human natural killer and $\mathrm{T}$ lymphocytes. Immunol Rev 1997; 155:105-17.

8 Kogure T, Fujinaga H, Niizawa A, Le Xuan Hai, Shimada $\mathrm{Y}$, Ochiai $\mathrm{H}$, et al. Killer-cell inhibitory receptors, $\mathrm{Y}$, Ochiai $\mathrm{H}$, et al. Killer-cell inhibitory receptors,
$\mathrm{CD} 158 \mathrm{a} / \mathrm{b}$, are upregulated by interleukin-2, but not interferon- $\gamma$ or interleukin-4. Mediators of Inflammation 1999;8:295-300.

9 Hoffman T. Natural killer function in systemic lupus erythematosus. Arthritis Rheum 1980;23:30-5.

10 Auer IO, Ziemer E, Sommer H. Immune status in Crohn's disease V. Decreased in vitro natural killer activity in peripheral blood. Clin Exp Immunol 1980;42:41-9.

11 Combe B, Pope R, Darnell B, Talal N. Modulation of natural killer cell activity in the rheumatoid joint and periphera blood. Scand J Immunol 1984;20:551-8.

12 Suzuki A, Ohosone Y, Obana M, Mita S, Matsuoka Y, Irimajiri S, et al. Cause of death in 81 autopsied patients with rheumatoid arthritis. J Rheumatol 1994;21:33-6.
13 Kim HA, Yoo CD, Baek HJ, Lee EB, Ahn C, Han JS, et al. Mycobacterium tuberculosis infection in a corticosteroidtreated rheumatic disease patient population. Clin Exp Rheumatol 1998;16:9-13.

14 Kogure T, Fuinaga H, Niizawa A, Shimada Y, Itoh T, Ochiai $\mathrm{H}$, et al. Rheumatoid arthritis complicated by mycobacterium tuberculosis. Are there characteristics predisposing to this association? Journal of Clinical Rheumatology 1999;5:17-21.

15 Orme IM, Anderson P, Boom WH. T cell responses to mycobacterium tuberculosis. J Infect Dis 1993;167:1481-97.

16 Tan JS, Canaday DH, Boom WH, Balaji KN, Schwander SK, Rich EA. Human alveolar T lymphocyte responses to mycobacterium tuberculosis antigens. Role for CD4+ and CD8+ cytotoxic $\mathrm{T}$ cells and relative resistance of alveolar macrophages to lysis. J Immunol 1997;159:290-7.

17 Johnson BJ, Ress SR, Willcox P, Pati BP, Lorgat F, Stead P, et al. Clinical and immune responses of tuberculosis patients treated with low-dose IL-2 and multidrug therapy. Cytokines and Molecular Therapy 1995;1:185-96.

18 Arnett FC, Edworthy SM, Bloch DA, McShane DJ, Fries JF, Cooper NS, et al. The American Rheumatism Association 1987 revised criteria for the classification of rheumatoid arthritis. Arthritis Rheum 1988;31:315-24.

19 Steinbrocker O, Traeger CH, Batterman RC. Therapeutic criteria in rheumatoid arthritis. JAMA 1949;140:659-62.

20 Ross G, Winchester RJ. Methods for enumerating lymphocyte population. In: Rose NR, Friedmann H, eds. Manual of clinical immunology. Washington: American Society for Microbiology, 1986:213.

21 Frohhn C, Schlenke P, Kirscner H. The repertoire of HLACw-specific NK cell receptors CD158a/b ( EB6 and GL183 ) in individuals with different HLA phenotypes. Immunology 1997;92:567-70.

22 Lanier LL. NK cell receptors. Annu Rev Immunol 1998;16: 359-93.

23 Mandelboim O, Malik P, Davis DM, Jo CH, Boyson JE, Strominger JL. Human CD16 as a lysis receptor mediating direct natural killer cell cytotoxicity. Proc Natl Acad Sci USA 1999;96:5640-4.

24 Nagler A, Lanier LL, Cwirla S, Phillips JH. Comparative studies of human FCR III-positive and negative natural killer cells. J Immunol 1989;143:3183-91.

25 Trinchieri G. Biology of natural killer cells. Adv Immunol 1989;47:187-376

26 Karsh J, Dorval G, Osterland CK. Natural cytotoxicity in rheumatoid arthritis and systemic lupus erythematosus. Clin Immunol Immunopathol 1981;19:437-46.

27 Neighbour PA, Grayzel AI, Miller AE. Endogenous and interferon-augmented natural killer cell activity of human peripheral blood mononuclear cells in vitro. Studies of patients with multiple sclerosis, systemic lupus erythematosus or rheumatoid arthritis. Clin Exp Immunol 1982;49: $11-21$.

28 Armstrong RD, Panayi GS. Natural killer cell activity in inflammatory joint disease. Clin Rheumatol 1983;2:243-9.

29 Goto M, Tanimoto K, Chihara T, Horiuchi Y. Natural killer cell-mediated cytotoxicity in Sjogrens syndrome and rheumatoid arthritis. Arthritis Rheum 1981;24:1377-82. 